\title{
JOTTINGS FROM THE BIOLOGICAL LABORATORY OF SYDNEY UNIVERSITY.
}

\author{
By Professor William A. Haswell, M.A., D.Sc.
}

No. 15. On a Simple Method of substituting Strong Alcohol for a Watery Solution in the Preparation of Specimens.

Lo Bianco has in the last part of the "Mittheilungen aus der Zoologischen Station zu Neapel," published an account of the methods which he follows in preparing those marvellous specimens of marine invertebrates for which the Station has long been famous all over the world. Many of the methods described have now been known to zoologists for some time, i.e., many of the methods of killing and fixing: it is more, perhaps, on account of the information which it gives us, as the result of a long series of trials, as to what re-agents are best adapted to each special group, with the best modes of application in each case, than as giving any entirely new formulæ, that the paper is of value.

As is well known, marine animals of different groups require to be dealt with in very different ways in order that we may preserve them in anything approaching to their natural form. Some may be taken by surprise, if we may use the expression, and killed so suddenly by some powerful poison that they remain fixed in a life-like shape. Others must be narcotised or paralysed by some such re-agent as chloroform, weak alcohol, or chloral hydrate, before the killing and fixing agent is used.

Whatever be the method of killing and fixing employed, there is in all delicate organisms a difficulty experienced in preventing 
shrinkage during the later processes which the specimens have to undergo before reaching the strong alcohol stage. In the most admirably fixed specimens shrivelling will often appear when alcohol is applied. "This difficulty is partly overcome, with great pains, by using a series of alcohols of ascending degrees of strength. But the result of this mode of procedure is not by any means always satisfactory.

Dr. Cobb, in a paper read before this Society, ${ }^{*}$ has described a method by which, in the case of small organisms, the shrinkage due to change from one fluid to another of a different density may be reduced to a minimum. In his differentiator we have an instrument of admirable simplicity for ensuring this result. But I have found that in practice the use of the differentiator involves a considerable expenditure of time. To get a specimen from distilled water to $90 \%$ alcohol for example, no fewer than eleven different mixtures of water and alcohol have to be made up and poured into the reservoir-tube.

A simple piece of apparatus which I have devised does away entirely with this - the gradual substitution for one another of the two fluids of different densities being effected automatically. An obvious mode of meeting the difficulty suggests itself at once. Why not have the second fluid falling into the first drop by drop, mixing thus very gradually with it and eventually replacing it? The difficulty in the way of this is that as each drop of the much lighter liquid enters the denser, violent though circumscribed currents are produced which are damaging to the delicate organisms we are dealing with.

The requisites for the method about to be described are-several reservoirs of glass or earthenware fitted with glass taps and having each a capacity of a gallon or more; some wide-mouthed bottles of a variety of sizes, fitted with perforated india-rubber stoppers, and some lengths of glass and india-rubber tubing.

* 'Proceedings,' Vol. v., p. 157. 
Two bottles of similar size are connected together by tubing in the way represented in the woodcut. One of these, A, we

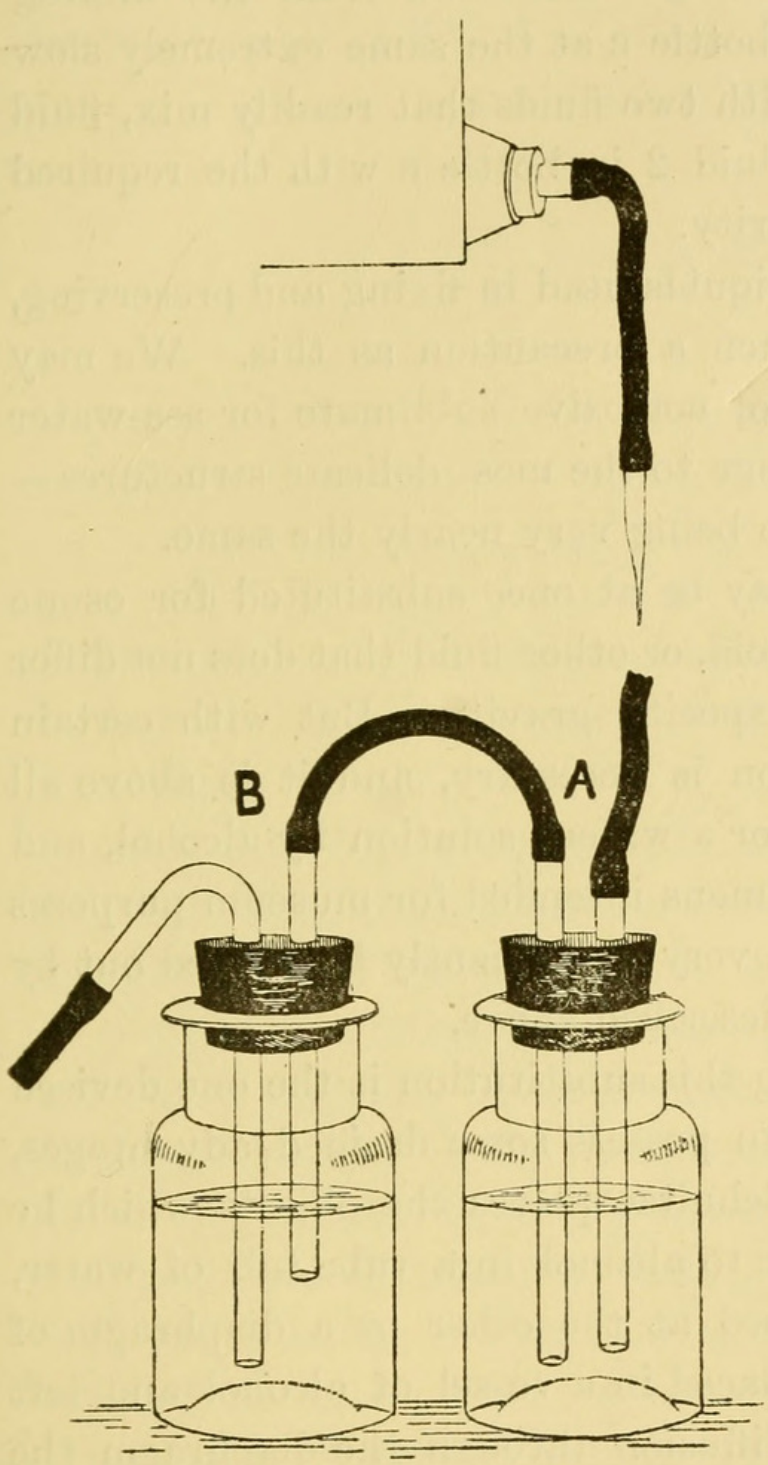
call the mixing bottle; the other, B, contains the objects, and must have a capacity equal to at least a hundred times the bulk of the latter. The objects are in fluid 1 , and it is desired to substitute fluid 2. Both bottles are filled, or partially filled, according to circumstances, with fluid 1 , and bottle $\mathrm{A}$ is connected with a reservoir of fluid 2. It is somewhat difficult by means of a tap to regulate the flow so that, let us say, one drop in five seconds will pass out of the reservoir; and it is much more convenient to effect this by intercalating in the supply pipe a section of glass tubing drawn out to the required degree of fineness (represented in the figure as disconnected from the proximal portion of the supply tube). The rate of flow through this narrow section of the tube can be further regulated by raising or lowering the reservoir or the mixing bottle, thus altering the pressure. With bottle $\mathbf{B}$ is connected an over-flow tube. Above the narrow section of glass tubing in the supply pipe it is well to have a piece of filter paper stretched across the mouth of the piece of tubing in the form of a diaphragm, and held in place by the overlapping india-rubber tubing. This prevents the possibility of the narrow part of the tube being choked up by any minute particles 
Fluid 2 thus enters into the mixing bottle at an extremely slow rate of flow, and becomes completely diffused, at first in extremely minute quantity, through fluid 1 . The fluid from the mixing bottle is meanwhile entering bottle в at the same extremely slow rate, and it is obvious that with two fluids that readily mix, fluid 1 may be made to replace fluid 2 in bottle $B$ with the required excessive slowness and regularity.

In the case of some of the liquids used in fixing and preserving, it is not necessary to use such a precaution as this. We may substitute saturated solution of corrosive sublimate for sea-water without the least risk of damage to the most delicate structures the specific gravity of the two being very nearly the same.

Similarly distilled water may be at once substituted for osmic acid solution, or $1 \%$ chromic acid, or other fluid that does not differ at all widely from water in specific gravity. But with certain fluids the gradual substitution is necessary, and it is above all necessary in replacing water or a watery solution by alcohol, and this in the case of large specimens intended for museum purposes as well as smaller objects, can very conveniently be carried out by the simple apparatus I have described above.

Another method of effecting this substitution is the one devised by Schultze; and this seems to possess some decided advantages, at least for small objects. Schultze places the objects which he wishes to transfer from water to alcohol in a tube full of water, plugged at one end, and closed at the other by a diaphragm of chamois skin. The tube is placed in a vessel of alcohol and left there until by a process of diffusion through the diaphragm the water in the tube becomes completely replaced by alcohol. The same material being used for the diaphragm, the time which will be occupied before complete substitution takes place will vary with the capacity of the tube and the diameter of its orifice; and a series of experiments and calculations would have to be made before this method could be used with the assurance of good results. Should it be desired to have the specimens in absolute alcohol at the end of the process, some calcined sulphate of copper may be placed in the outer vessel. 


\section{$2 \mathrm{BHL}$ Biodiversity Heritage Library}

Haswell, W A. 1892. "Jottings from the biological laboratory of Sydney

University." Proceedings of the Linnean Society of New South Wales 6, 433-436. https://doi.org/10.5962/bhl.part.29900.

View This Item Online: https://www.biodiversitylibrary.org/item/30437

DOI: https://doi.org/10.5962/bhl.part.29900

Permalink: https://www.biodiversitylibrary.org/partpdf/29900

\section{Holding Institution}

MBLWHOI Library

\section{Sponsored by}

MBLWHOI Library

\section{Copyright \& Reuse}

Copyright Status: NOT_IN_COPYRIGHT

This document was created from content at the Biodiversity Heritage Library, the world's largest open access digital library for biodiversity literature and archives. Visit BHL at https://www.biodiversitylibrary.org. 